\title{
Selective Leaching of Vanadium from Vanadium Slag using Organic Acids
}

\author{
J. Ntita, W. Nheta, and Petrus V. Staden
}

\begin{abstract}
Large amounts of vanadium bearing slags are produced during steel making and discarded to the environment. Bioleaching has proved that it is an environmentally friendly route which has been lately used for recovery of metals. The leaching of vanadium from a roasted slag was studied using gluconic, citric and oxalic acids. The vanadium slag was roasted at $900^{\circ} \mathrm{C}$ in presence of $\mathrm{Na}_{2} \mathrm{CO}_{3}$ prior to leaching. The effect of acid concentration, solid/liquid ratio, particles size and temperature were investigated. It was observed that a concentration of $150 \mathrm{mM}$ for gluconic acid and $100 \mathrm{mM}$ of citric and oxalic acid, $2 \%$ of $\mathrm{S} / \mathrm{L}$ ratio, $-38 \mu \mathrm{m}$ and temperature of $45^{\circ} \mathrm{C}, 91,86$ and $81 \%$ of vanadium were recovered from gluconic, citric and oxalic acid respectively. Recovery of vanadium using gluconic acid is affected more by the acid concentration compared to citric and oxalic acids. The solid/ liquid ratio as well as the particle size increase have a negative effect on the recovery of each acid and the temperature increase allows to enhance the recovery.
\end{abstract}

Keywords — Leaching, Organic acids, Slag, Vanadium.

\section{INTRODUCTION}

The steelmaking industry produces large amounts of waste such as vanadium bearing slags (containing up to $12-25 \%$ of vanadium pentoxide) that can be used as a source of vanadium [1]. Vanadium slags is one of the most significant secondary sources of the metal and contribute to $58 \%$ of vanadium production [2]. In the slag, vanadium is generally found as vanadium pentoxide $\left(\mathrm{V}_{2} \mathrm{O}_{5}\right)$ which is refractory and very difficult to leach. Therefore, the roasting-leaching process using sodium salts (usually $\mathrm{NaCl}, \mathrm{Na}_{2} \mathrm{CO}_{3}$, and $\mathrm{Na}_{2} \mathrm{SO}_{4}$ ) is the most applied recovery process. During this process, vanadium is precipitated from the mineral structure and oxidized into pentavalent vanadium oxide and then sodium oxide obtained from sodium reacts with vanadium pentoxide to form soluble sodium vanadate [3]-[5].

Manuscript received September, 2017.

J. Ntita is with the Department of Metallurgy, University of Johannesburg, 2028 Doornfontein, South Africa (ntitajoelle@ gmail.com).

W. Nheta is with the Department of Metallurgy, University of Johannesburg, 2028 Doornfontein, South Africa (wnheta@uj.ac.za).

P van Staden is with the Mintek, 200 Malibongwe Drive, Randburg 2125, South Africa (petrusv@mintek.co.za)
Previous studies have reported that Xin-sheng Li and Bing Xie extracted vanadium from high calcium vanadium slag by direct roasting and soda leaching. Recovery of $90 \%$ of vanadium was reached at the optimum conditions of roasting and leaching [6]. Recovery of more than $80 \%$ of vanadium from a steel slag was also obtained by Mahdavian and his coworkers (2006) using a sodium carbonate roasting-leaching method [7]. However, all these works were done using strong acids which are not environmentally friendly. A New friendly method 'bioleaching' have also been exploited in the recovery of vanadium [8], [9]. Different species of microbial and bacterial systems have been used over the years for the recovery of metals in general and particularly vanadium from its occurrences (ores, slags, spent catalysts) and it has proved that bioleaching is an efficient technology for leaching of vanadium [10].

During the bioleaching process, formation of either organic or inorganic acids induce the mobilisation of vanadium. Species such as Aspergillus niger, tends to manufacture organic acids such as gluconic, citric, oxalic acids in enough quantities to dissolve metals [11], [12].

This paper is aimed at mimicking a bioleaching process with formation of gluconic, citric, oxalic acids using commercial acids and investigate the behaviour of each acid in the leaching process.

\section{MATERIALS AND METHODS}

\section{A. Materials}

Rhovan Glencore Mine provided a vanadium slag from their steelmaking plant. The chemical composition of the slag before and after roasting were determined by X-ray Fluorescence spectrometer (XRF) Rigaku ZSX Primus II. Mineral phases identification was performed using X-ray Diffraction (XRD) Rigaku Ultima IV. Analysis of vanadium from the lea ched samples was processed using atomic absorption spectroscopy (AAS). Analytical high-grade reagents supplied by MERCK were used for all the experiments.

\section{B. Methods \\ Roasting process}

The sample was pulverised, mixed with sodium carbonate in different ratios $(10-40 \%)$, pelletized and roasted at different temperatures $\left(800-1000^{\circ} \mathrm{C}\right)$ for two hours in a muffle furnace to convert the vanadium into a more soluble form. The slag 
was cooled down inside the furnace for twelve hours. The samples were then leached in gluconic, citric and oxalic acids at $50 \mathrm{mM}$ and analysed. The sample with the maximum leached vanadium $\left(900^{\circ} \mathrm{C}, 20 \%\right)$ was then analysed using XRD and then pulverised to $-75 \mathrm{um}$ for further experiments.

\section{Leaching process}

The roasted slag was pulverised to $100 \%-75 \mu \mathrm{m}$ and leached using gluconic, citric and oxalic acids at different concentrations $(50,100,150,200 \mathrm{mM})$, different solid-liquid ratios $(2,4,6,8$ and $10 \mathrm{wt} \%)$, different particles size $(-38 \mu \mathrm{m}$, $75+53 \mu \mathrm{m},-150+106 \mu \mathrm{m})$ and different leaching temperatures $\left(25,35\right.$ and $\left.45^{\circ} \mathrm{C}\right)$. All the experiments were done under an agitation rate of 150 rotation per minute and a leaching time of one hour. A $250 \mathrm{ml}$ conical flask in a shaking water bath was used in the leaching process.

\section{RESULTS AND DISCUSSION}

\section{A. Characterisation of the Roasted Slag}

The chemical composition of the roasted slag was obtained using XRD and the results are shown in Table I. The roasted slag contains a considerable amount of vanadium oxide $(3.71 \%)$ which is equivalent to $5.13 \%$ of V. Major elements present are aluminium (50.25\%), calcium (13.64\%) and magnesium $(6.1 \%)$ and some minor compounds.

TABLE I: CHEMICAL COMPOSITION OF THE SLAG

\begin{tabular}{lllllll}
\hline \hline Compound & $\mathrm{Na}_{2} \mathrm{O}$ & $\mathrm{MgO}$ & $\mathrm{Al}_{2} \mathrm{O}_{3}$ & $\mathrm{SiO}_{2}$ & $\mathrm{CaO}$ & $\mathrm{V}_{2} \mathrm{O}_{5}$ \\
\hline Wet (\%) & 24.3 & 6.1 & 50.2 & 0.60 & 13.64 & 3.71 \\
\hline \hline
\end{tabular}

The XRD pattern and the major minerals present in the sample are shown in Fig. 1. Fig. 1 illustrates that insoluble phases from the raw slag such as vanadium oxide and calcium vanadium oxide were changed to soluble phases such as sodium vanadate and sodium pentavanadate during roasting in the presence of $\mathrm{Na}_{2} \mathrm{CO}_{3}$.

\section{B. Leaching Experiments}

\section{The Effect of Acid Concentration}

The effects of the gluconic, citric and oxalic acid concentration on $\mathrm{V}$ leaching efficiency was investigated in the range of $50-200 \mathrm{mM}$ and the results are presented in Fig. 2. As acid concentration increases, the percent vanadium leached also increases until a concentration of $150 \mathrm{mM}$ for gluconic acid and $100 \mathrm{mM}$ for citric and oxalic acids is reached. Further increase in the acid concentration causes no significant increase in the recovery of Vanadium.

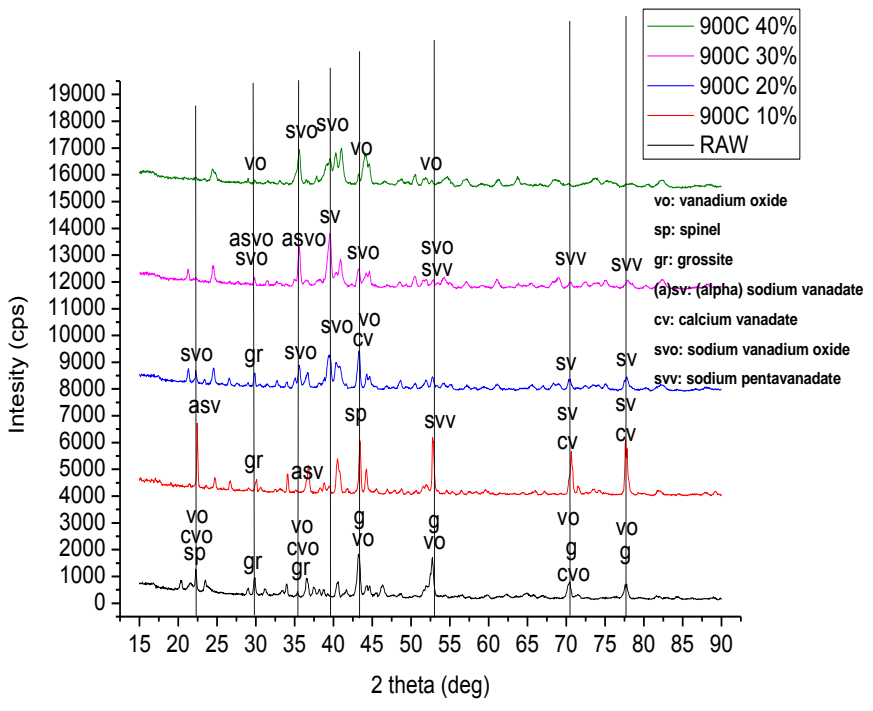

Fig. 1. XRD pattern of the raw and roasted slags

This can be justified by the increase of the appearance rate of the products caused by the acid concentration increase. Therefore, the product reaches the saturation value near the solid particle with formation of difficult soluble solid film layers around the particles due to the increase of the appearance rate of the products. This may also be due to the decrease in the amount of hydrogen ions in the medium attributed to the reduction of the water amount in the media.

Acid concentration has more effect when using gluconic than citric and oxalic acids. Therefore, it is more economical to use a low concentration of citric and oxalic acids (100mM) compared to gluconic acid (150mM).

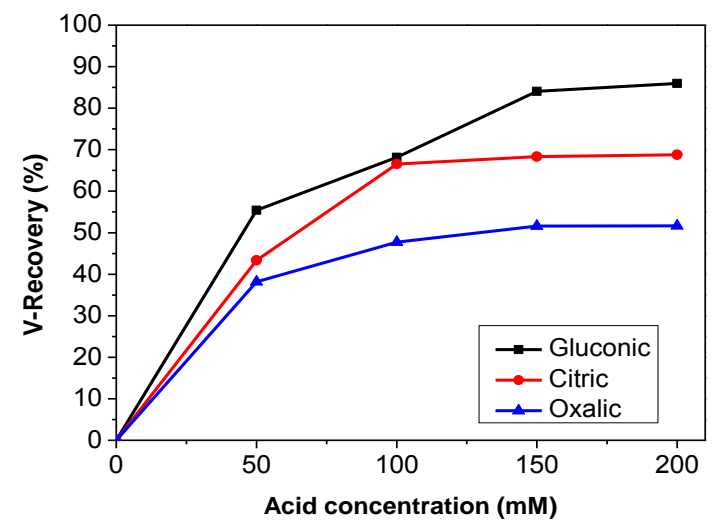

Fig. 2: Effect of concentration on dissolution of vanadium

\section{The Effect of Solid-Liquid Ratio}

The effect of solid-liquid (S/L) ratio was studied in the rage of $2-10 \mathrm{wt} \%$ and the results are shown in Fig. 3. The vanadium recovery decrease with the increase of the S/L ratio. The amount of the dissolved solid per unit liquid increases when solid/liquid ratio is increased, thus the leaching rate decreases. Decreasing the S/L ratio enhances the diffusion of the reaction medium and makes the reaction more complete, which is advantageous for leaching. At high S/L ratio, the leaching slurry is more viscous and therefore the ions diffusion is slower resulting in low leaching efficiencies. For all acids, it 
was observed that the maximum recovery was reached at $2 \%$ S/L.

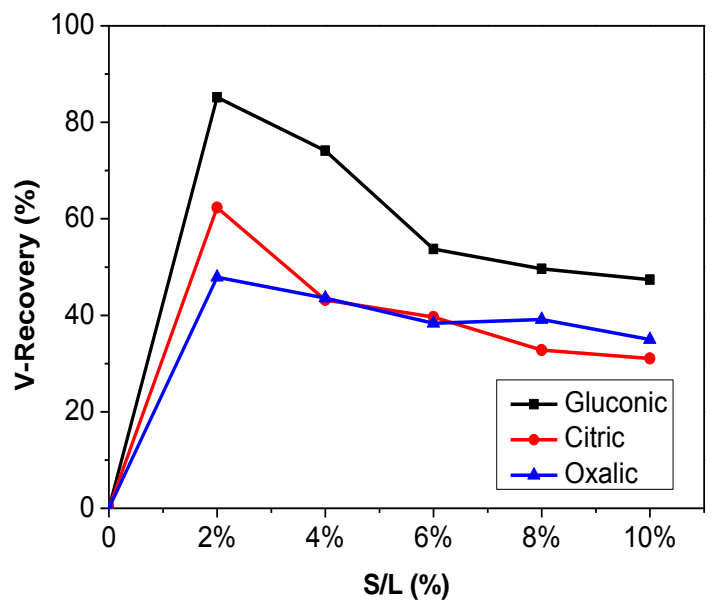

Fig 3: Effect of S/L on dissolution of Vanadium

\section{The Effect of Particles Size}

The effect of particle size was investigated in different particles size fractions and the results are illustrated in Fig. 4. It is shown that the particles size has significant influence on the dissolution of vanadium. The leaching rate greatly increases with decreasing particles size. This is due to the increase in the contact surface per unit weight of solid. The particle size of $-38 \mu \mathrm{m}$ gave the highest leaching efficiency compared to the higher particles size used for all the three acids.

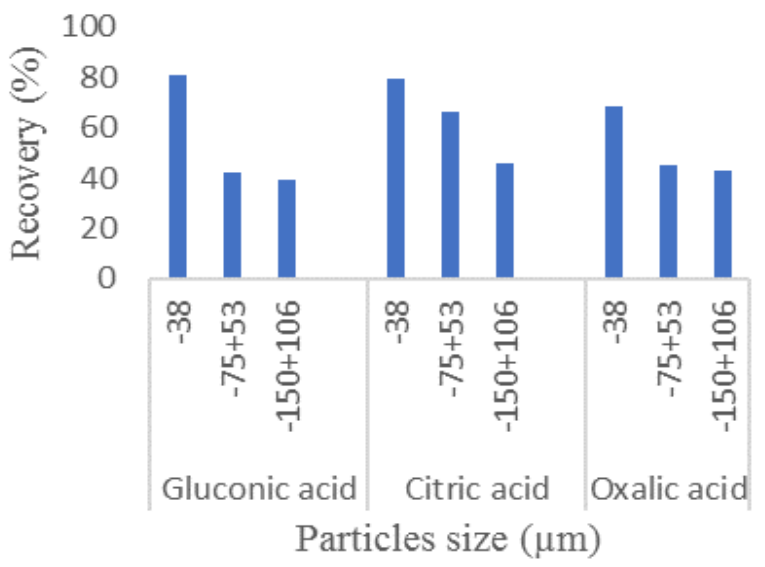

Fig. 4. Effect of particles size on dissolution of vanadium.

\section{The Effect of Temperature}

The leaching experiments were carried out at temperatures of $25-45^{\circ} \mathrm{C}$ to investigate the impact of temperature on the leaching. Results showed temperature to be important for leaching yields of $\mathrm{V}$ with a positive effect. Vanadium dissolution increased with the temperature increase. This is due to the increase in the ions diffusion rate between the leaching reagents and the slag. An average of 90, 88 and $80 \%$ recovery of $\mathrm{V}$ were obtained at $45^{\circ} \mathrm{C}$ for gluconic, citric and oxalic acids respectively.

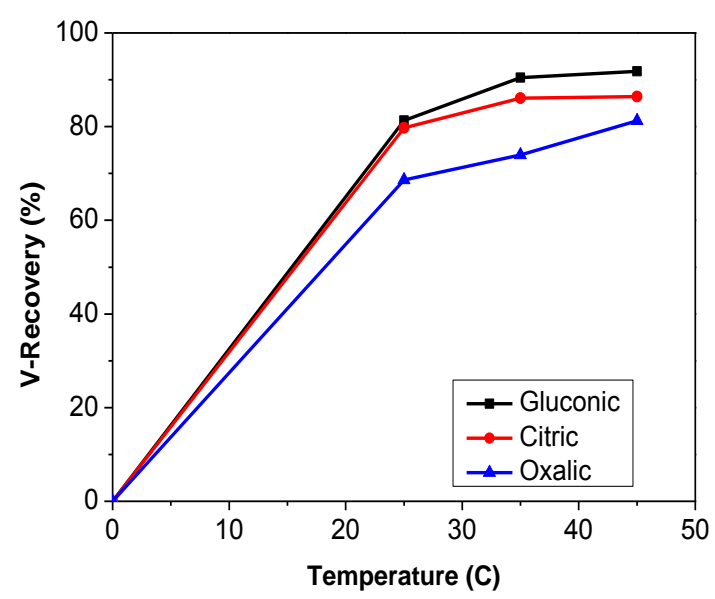

Fig. 5. Effect of temperature on dissolution of vanadium

\section{CONCLUSION}

Leaching of vanadium from slag by microorganism producing gluconic, citric and oxalic acids was mimicked using commercial acids and high recoveries of vanadium were obtained. The acids produced reach their highest concentration during the exponential and/or stationary phase of the microorganisms. The results of this study have proven that vanadium can be recovered using the commercial gluconic, citric and oxalic in the same concentration as the one produced by microorganisms. The results showed that roasting temperature and $\% \mathrm{Na}_{2} \mathrm{CO}_{3}$, acid concentration, $\mathrm{S} / \mathrm{L}$ ratio, leaching temperature and particle sizes have great influence on the leaching of vanadium. However, there is need to investigate the leaching kinetics and model this process.

\section{REFERENCES}

[1] C. K. Gupta, and N. Krishnamurthy, "Extractive Metallurgy of Vanadium," Elsevier, Netherlands, pp. 151-320, 1992.

[2] B.V.R. Raja, "Vanadium market in the world," Steelworld, 13(2), pp. 19-22, 2007.

[3] H.L. Lin, "Study on vanadium extraction from Fangshankou bone coal in GansuDunhuang," Chengdu University of Technology: Chengdu, China, 2000.

[4] Y. Zhang, B.W. Fan, and D.P. Peng, "Research of Precipitation Polyammonium Vanadate from extraction solution of acid-leaching bone coal," Chin. J. Rare Met., (25), pp. 157-160, 2001.

[5] D. Liu, X. Xue, and H. He, "The effect of chromium on the roasting process of vanadium extraction," Institute of metallurgical resources and environmental engineering, Northeastern University, Shenyang 110819, China, dongda 1985.

[6] X.S. Li, and B. Xie, "Extraction of vanadium from high calcium vanadium slag using direct roasting and soda leaching," International Journal of Minerals, Metallurgy and Materials., vol 19, no. 7, pp. 595, July 2012

[7] A. Mahdavian, A. Shafyei, E.K. Alamdari, D.F. Haghshenas, "Recovery of vanadium from Esfahan steel company steel slag; optimizing of roasting and leaching parameters," vol 3. pp. 17-21, 2006.

[8] S.M.J. Mirazimi, Z. Abbasalipour, F. Rashchi, "Vanadium removal from LD converter slag using bacteria and fungi," Journal of Environmental Management (153), pp. 144-151, 2015.

[9] B. Beolchini, V. Fonti, F. Ferella, F. Veglio, "Bioleaching of Nickel, Vanadium and Molybdenum from spent refinery catalysts," Article in advanced materials research, May 2009. 
[10] J. Ntita, W. Nheta, "Investigation on the mechanisms of bio-processing vanadium slags," 2017.

[11] P. Bosshard, R. Bachofen, H. Brandl, "Metal leaching of fly ash from municipal waste incineration by Aspergillus niger," Environ. Sci. Technol. (30), pp. 3066-3070. 1996.

[12] J. Doshi, D. Mishra, "Bioleaching of lateritic nickel ore using a heterotrophic microorganism," India: national institute of technology; M.Sc. thesis, pp. 20-30, 2007. 